\title{
Introduction to Best and Next Practices in Online Education: Opportunities and Challenges Minitrack
}

\author{
Mahesh S. Raisinghani \\ Texas Woman's University \\ mraisinghani@twu.edu
}

\author{
Efosa C. Idemudia \\ Arkansas Tech University \\ eidemudia@atu.edu
}

\section{Minitrack Introduction}

The proliferation of Web-based technologies during the last decade may have given the impression of widespread changes in educational practices. In fact, we have only begun to scratch the surface of experiencing the vast impact these technologies could have on education. Viewed separately, Web-based technologies offer exciting possibilities for expanding the capacity to provide access to instruction and knowledge worldwide. However, and perhaps more importantly, viewing these technological advancements in a more dynamic context, forces educators and researchers to rethink the fundamental processes of teaching and learning . It's not just a simple matter of using a technical tool to supply time and place ubiquity but to accept the challenge of understanding the implications for the entire educational spectrum. Web-based teaching and learning begs the question of what exactly these technologies means for learners, teachers, program designers, academic experts, technical and administrative staff, institutional decision makers, training managers, publishers, and others. Although a considerable amount of exploration has been conducted regarding web-based learning technologies, the breadth and scope for dialogue and experimentation needs to be broadened. This mini-track provides a place for the dialogue and support of a diverse community interested in taking the challenge further.

\section{Overview of Papers in this Minitrack}

The three papers presented in this minitrack address several important issues in this research area such as the changing dimensions of the web based learning and teaching technologies, models, methods, and frameworks; sharing educational experiences and situations including online education; business simulation; and mobile learning.

\begin{tabular}{|c|l|}
\hline $\begin{array}{c}\text { Manuscript \# } \\
504\end{array}$ & \multicolumn{1}{c|}{\begin{tabular}{c}
\multicolumn{1}{c|}{ Manuscript Title } \\
Al Thinking for Cloud Education \\
Platform with Personalized Learning
\end{tabular}} \\
\hline 949 & $\begin{array}{l}\text { Flow in Business Simulation Games: } \\
\text { Comparison between Online and } \\
\text { Face-to-Face MBA }\end{array}$ \\
\hline 991 & $\begin{array}{l}\text { Enabling Workers to Enter Industry } \\
\text { 4.0: A Layered Mobile Learning } \\
\text { Architecture }\end{array}$ \\
\hline
\end{tabular}

